\title{
Insecticidal Effect Of Adansonia digitata Stem Bark And Leaf Powders On Dinoderus porcellus
}

\section{*JOHN,WC; ISHAYA, M; OLORI-OKE, O; UKANYIRIOHA, CJ; CHOMINI, MS; KYAHARLE, BS}

\author{
Federal College of Forestry, Jos, Plateau State, Nigeria \\ *Corresponding Author: Email: jwaltee@gmail.com; Tel: +2348064487369
}

\begin{abstract}
This study evaluated insecticidal activity of different doses of Adansonia digitata stem bark and leaf powders on yam beetles dinoderus porcellus. Obtained plant parts from Federal colloge of Forestry, Jos were pulverized into powders. Phytochemical constituents of the plant were extracted by Soxhlet extraction and identified using standard procedure. Mortality testing was done by exposing dinoderus porcellus to yam chips mixed with various doses of Adansonia digitata stem bark and leaf powders. Yam chips without treatment served as the control. The experiments were laid out in randomized complete design with three replications. Data obtained were analysed using analysis of variance $(\mathrm{P} \leq 0.05)$. The result of the phytochemical examination of ethanolic extract of $A$. digitata revealed the presence of saponins, phenols, tannins and alkaloids flavonoids. The finding revealed the superiority of yam chips mixed stem bark and leaf powders over the untreated. The effect of plant extracts on percentage mortality showed significant difference $(\mathrm{p}<0.05)$ among the treated and control. The sample treated with $15 \mathrm{~g}$ of $A$. digitata stem-bark powder gave the highest mortality. The research hence recommends the use of $15 \mathrm{~g}$ of A. digitata stem-bark powder in elimination of Dinoderus porcellus infecting yam chips.
\end{abstract}

DOI: $\underline{\text { https://dx.doi.org/10.4314/jasem.v25i2.25 }}$

Copyright: Copyright () 2021 John et al.. This is an open access article distributed under the Creative Commons Attribution License (CCL), which permits unrestricted use, distribution, and reproduction in any medium, provided the original work is properly cited.

Dates: Received: 12 December 2020; Revised: 26 January 2021; Accepted: 12 February 2021

Keywords: A. digitata, Insecticida, Mortality, flavonoid, Dinoderus porcellus

Yam cultivated in Nigeria belong to genus Dioscorea and species farmed in Nigeria include the D. rotundata (white yam), D. cayenesis, (yellow or guinea yam) and D. alata (water yam) (Amusa et al., 2003). The organoleptic qualities of yam makes it the most consummed staple food and provide estimated 350 dietary calories per person daily. Globally, over 30 million tonne per annum of yam is cultivated, out of which Nigeria alone account for 22 million tonne (FAO, 1998). Inspite of this huge cultivation in Nigeria, demand exceed supply always. To mitigate this, yam tubers are processed into chips to reduce post-harvest losses and to provide raw materials for industries in agro businesses. However, the yam chips are heavily infested by insect pests leading to great losses. The insect $D$. porcellus is a major pest of stored farm produce of many roots and tubers such as yam in West Africa (Loko et al., 2019). D. porcellus destroys yam chips by making holes, thereby transforming the internal parts of the yam into powder, which adversely affects their quality and market value. The effect of $D$. porcellus on newly dried yams under laboratory investigation led to weight loss of $29.5 \%$ in $4-5$ months (Adesuyi, 1979). Furthermore, infestation of stored yam chips by $D$. porcellus makes yam floors like amala undesirabe for consumer (Babarinde et al., 2013). Synthetic pesticide application is the most common means of control employed by farmers against $D$. porcellus associated with stored yam chips (Vernier et al., 2005). Interestingly, several of these pesticide are not produced specifically to protect yam chips in storage and food poisoning cases has grown immensely due to their misused (Adeleke, 2009). Faced with this challange, search for noval botanical with insecticidal potental is urgently needed to safe the environment and human health. A typical important plant is Adansonia digitata also called African Baobab, Adansonia digitata occurs naturally in Africa and therapeutically, it pulverized powders are used to treat all forms of diseases in Africa (Zagga et al., 2018). Therefore, the aim of this work is to investigate the insecticidal activities of Adansonia digitata leaf and stem bark powders against $D$. porcellus.

\section{MATERIALS AND METHODS}

Sample Collection and Preparation of Adansonia digitata Plant Parts: The leaves and stem bark of Adansonia digitata were collected in Federal College 
of Forestry Jos, Plateau state Nigeria. The plant parts of Adansonia digitata were collected in clean polythene bag and were taken to the Herbarium of Federal College of Forestry Jos for identification and authentication. After identification, the collected materials were washed and dried under shade to avoid active compounds degradation by sunlight. Fine powder of plant materials were obtained after drying by grinding using mortar and pistle and followed by sieving, (Loko et al., 2017).

Extracts Preparation: Soxhlet extraction with ethanol was done using fifty gram of dried and pulverized leaf and stem bark Adansonia digitata samples. Distillation was carried out and plant extracts collected through rotary evaporation and kept at $4{ }^{\circ} \mathrm{C}$ in a refrigerator.

Phytochemical Screening of Adansonia digitata Leaf and Stem Bark Extract: The Adansonia digitata leaf and stem Bark extracts were examined for the presence phytochemicals using standardized procedures described by Harborne (1984).

Processing Of Yam Chips: This was carried out using the method of Babajide et al. (2006). The yam tubers were washed with water to remove sand and other unwanted elements, and then peeled using sterile knife. The tubers were cut into slices of $2 \mathrm{~cm} \mathrm{x} 4 \mathrm{~cm}$. The yam slices obtained were pre-cooked in water at a temperature of $50^{\circ} \mathrm{C}$ for 2 hours. They were also allowed to be macerated in the pre-cooking water for 24 hours in order to soften them. The slices were strained and dried in the oven at $60^{\circ} \mathrm{C}$ for 3 days in order to have 12 to $14 \%$ of final moisture content. The chips samples were sterilized at $105^{\circ} \mathrm{C}$ for 2 hours in order to kill the hidden insects and their eggs. The samples were exposed to an ambient temperature for 1hour. The dried chips obtained were put in a dry and clean polythene bags and stored in the laboratory at ambient temperature.

Collection and Breeding of Dinoderus porcellus: The procedure described by Onzo et al. (2015) was adopted. Infested yam chips were purchase from Yandoya market in Jos North L.G.A. and identified at the Entology Laboration Federal College of Forestry Jos, Plateau state Nigeria under microscope with the aid of insect atlas. The collected insect adultes and eggs were transferred into a plastic bowl and maintained on healthy yam at room temperature to enhance their development. The plastic container was covered with a muslin cloth, allowing an adequate aeration and preventing insects from running out and kept on a stable table in the laboratory. Newly emerged adult beetles were used for the experiments.
Mortality Test: Mortality test was conducted according to the methodology used by Chebet et al. (2013). Leaf and stem bark powders of Adansonia digitata $(5 \mathrm{~g}, 10 \mathrm{~g}$ and $15 \mathrm{~g})$ were mixed with $100 \mathrm{~g}$ of disinfected yam chips in plastic containers while the control had $100 \mathrm{~g}$ of untreated sterile yam chips. The treated and untreated yam chips in the plastic containers were inoculated witt twenty adults of Dinoderus porcellus. Each box was covered with a transparent muslin cloth to prevent the insects from escaping. Treatments were set up in a completely randomized design with three replicates. The set up was observed after 24, 48, 72, 96 and 120 hours of infestation and dead adults counted. The adult mortality rate was calculated according to the formula of Asawalam et al. (2006).

$$
\% \text { Motality }=\frac{\text { ND dead }}{\text { ND introduced }} \times 100
$$

Where ND dead is number of $\mathrm{D}$. porcellus dea, ND introduced is number of $\mathrm{D}$. porcellus introduced

Data Analysis: Data collected was analyzed using analysis of variance (ANOVA) to check for significant difference between the different treatments at $5 \%$ significant difference. The means was separated using Duncan test.

\section{RESULTS AND DISCUSSION}

The result of the phyto-chemical examination of ethanolic extract of $A$. digitata plant leaf and stem bark in Table 1 revealed the presence of saponins, phenols, tannins and alkaloids flavonoids. This finding concord with work of Musau et al. (2016) who showed the presence of Steroids, saponins, glycosides, alkaloids and flavonoid in A. digitata seed leaf. Similar results were reported by Shukla et al. (2001), the indicated the presence of flavonoids, terpenoids, sterols in different parts of $A$. digitata including the seed oil.

Table 1:Phytochemical Constituents of Ethanolic Extract of

\begin{tabular}{lll} 
& \multicolumn{2}{c}{ Adansonai Digitata } \\
\hline S/N & Phytochemical & Presence \\
\hline 1 & Saponin & + \\
2. & Flavonoid & + \\
3. & Phenol & + \\
4. & Alkaloid & + \\
5. & Gelatin & - \\
6. & Tannin & + \\
7 & Glycoside & + \\
8. & Terpenoids & - \\
\hline
\end{tabular}

The results on percentage mortality as presented in Table 2 showed that the insecticidal effect from $A$. digitata leaf powder were significantly $(\mathrm{p}<0.05)$ different at days 1 to 5 . Results of the study thus 
revealed that mean values recorded for each treatment increased as the days increased from day one to five. The highest mean value for day one, two, four and five was obtained from $15 \mathrm{~g}$, this was followed by $10 \mathrm{~g}>5 \mathrm{~g}>$ $0 \mathrm{~g}$ (control). Subsequently, a change in mortality rate was later obtained from day 3 and the order of increase were $10 \mathrm{~g}>15 \mathrm{~g}>5 \mathrm{~g}>0 \mathrm{~g}$ (control). This revealed that the phytochemicals shown in adansonia digitata plants powder has insectidical activites against adult $D$. porcellus. Kumar et al. (2015) reported similar phytochemicals in celery seed oil exhibiting larvicidal action against Aedes aegypti L. The current finding is in agreement with work of Loko et al. (2017) which reported leaves of Blighia sapida, Khaya senegalensis and Bridelia ferruginea were active against $D$. porcellus.

Table 2: Percent insecticidal effects of A. digitata leaf powder on percentage mortality of $D$. porcellus at different day's interval

\begin{tabular}{llllll}
\hline \multirow{2}{*}{ Treatment } & \multicolumn{5}{c}{ MORTALITY AND TIME } \\
\cline { 2 - 6 } & Day 1 & Day 2 & Day 3 & Day 4 & Day 5 \\
\hline $\mathbf{5 g}$ & $6.67^{\mathbf{b}}$ & $18.33^{\mathrm{b}}$ & $26.67^{\mathrm{b}}$ & $50.00^{\mathrm{b}}$ & $85.00^{\mathbf{c}}$ \\
$\mathbf{1 0 g}$ & $13.33^{\mathrm{a}}$ & $21.67^{\mathrm{ab}}$ & $36.67^{\mathrm{a}}$ & $78.33^{\mathrm{a}}$ & $91.67^{\mathbf{b}}$ \\
$\mathbf{1 5 g}$ & $15.00^{\mathrm{a}}$ & $26.67^{\mathrm{a}}$ & $35.00^{\mathrm{a}}$ & $80.00^{\mathrm{a}}$ & $100.00^{\mathrm{a}}$ \\
Control (0g) & $0.00^{\mathrm{c}}$ & $0.00^{\mathbf{c}}$ & $1.33^{\mathrm{c}}$ & $133^{\mathrm{c}}$ & $1.67^{\mathrm{d}}$ \\
$\mathbf{S E}$ & $\mathbf{1 . 8 6}$ & $\mathbf{2 . 0 4}$ & $\mathbf{2 . 7 7}$ & $\mathbf{3 . 9 1}$ & $\mathbf{1 . 6 8}$ \\
\hline
\end{tabular}

Means on the same column with the same superscript do not differ significantly from each other $(P=0.05)$. Where: $\mathrm{SE}=\mathrm{Standard}$ error

Table 3: Percent insecticidal effects of A. digitata stem bark powder on percentage mortality of $D$. porcellus at different day's interval

\begin{tabular}{llllll}
\hline \multirow{2}{*}{ Treatment } & \multicolumn{5}{c}{ MORTALITY AND TIME } \\
\cline { 2 - 6 } & Day 1 & Day 2 & Day 3 & Day 4 & Day 5 \\
\hline $\mathbf{5 g}$ & $33.33^{\mathbf{b}}$ & $46.67^{\mathbf{b}}$ & $70.00^{\mathbf{b}}$ & $91.67^{\mathbf{b}}$ & $98.33^{\mathrm{a}}$ \\
$\mathbf{1 0 g}$ & $40.00^{\mathrm{b}}$ & $58.33^{\mathrm{a}}$ & $93.33^{\mathrm{a}}$ & $100.00^{\mathrm{a}}$ & $100.00^{\mathbf{a}}$ \\
$\mathbf{1 5 g}$ & $53.33^{\mathrm{a}}$ & $65.00^{\mathrm{a}}$ & $98.33^{\mathrm{a}}$ & $100.00^{\mathrm{a}}$ & $100.00^{\mathbf{a}}$ \\
Control (0g) & $0.00^{\mathrm{c}}$ & $0.00^{\mathrm{c}}$ & $2.00^{\mathrm{c}}$ & $2.33^{\mathbf{c}}$ & $2.00^{\mathbf{b}}$ \\
$\mathbf{S E}$ & $\mathbf{2 . 7 6}$ & $\mathbf{3 . 4 4}$ & $\mathbf{3 . 1 3}$ & $\mathbf{0 . 9 4}$ & $\mathbf{0 . 8 8}$ \\
\hline
\end{tabular}

Means on the same column with the same superscript do not differ significantly from each other $(P=0.05)$. Where: $\mathrm{SE}=\mathrm{Standard}$ error

Table 4: Mean synergetic effects of A. digitata leaves and stem bark powder on percentage mortality of $D$. porcellus at different day's

\begin{tabular}{llllll}
\multicolumn{5}{c}{ interval } \\
\cline { 2 - 6 } Treatment & \multicolumn{5}{c}{ MORTALITY AND TIME } \\
\cline { 2 - 6 } & Day 1 & Day 2 & Day 3 & Day 4 & Day 5 \\
\hline $\mathbf{5 g}$ & $15.00^{\mathrm{b}}$ & $38.33^{\mathrm{b}}$ & $65.00^{\mathrm{b}}$ & $90.00^{\mathrm{a}}$ & $93.33^{\mathrm{a}}$ \\
$\mathbf{1 0 g}$ & $28.33^{\mathrm{a}}$ & $56.67^{\mathrm{a}}$ & $81.67^{\mathrm{a}}$ & $93.33^{\mathrm{a}}$ & $95.00^{\mathrm{a}}$ \\
$\mathbf{1 5 g}$ & $33.33^{\mathrm{a}}$ & $58.33^{\mathrm{a}}$ & $86.67^{\mathrm{a}}$ & $93.33^{\mathrm{a}}$ & $100.00^{\mathrm{a}}$ \\
Control (0g) & $0.00^{\mathrm{c}}$ & $0.67^{\mathrm{c}}$ & $1.33^{\mathrm{c}}$ & $2.33^{\mathrm{b}}$ & $2.33^{\mathrm{b}}$ \\
$\mathbf{S E}$ & $\mathbf{3 . 4 4}$ & $\mathbf{4 . 3 4}^{\mathbf{3}}$ & $\mathbf{4 . 0 0}$ & $\mathbf{2 . 8 0}$ & $\mathbf{2 . 2 5}$ \\
\hline
\end{tabular}

Means on the same column with the same superscript do not differ significantly from each other $(P=0.05)$. Where: $\mathrm{SE}=\mathrm{Standard}$ error

Table 5: Mean insecticidal effects of $A$. digitata leaves powder; stem-bark powder and leaves powder + stem-bark powder on percentage mortality of D. porcellus at different day's interval

\begin{tabular}{llllll}
\hline & \multicolumn{5}{c}{ MORTALITY AND TIME } \\
\cline { 2 - 6 } Treatment & Day 1 & Day 2 & Day 3 & Day 4 & Day 5 \\
\hline Leaf powder & $8.75^{\mathbf{b}}$ & $16.67^{\mathbf{b}}$ & $24.92^{\mathbf{b}}$ & $52.42^{\mathbf{a}}$ & $69.58^{\mathbf{a}}$ \\
Stem-bark powder & $31.67^{\mathbf{a}}$ & $42.50^{\mathbf{a}}$ & $65.92^{\mathbf{b}}$ & $73.50^{\mathbf{a}}$ & $75.08^{\mathbf{a}}$ \\
Leaf powder + Stem-bark powder & $19.17^{\mathrm{ab}}$ & $38.50^{\mathbf{a}}$ & $58.67^{\mathbf{b}}$ & $69.75^{\mathbf{a}}$ & $72.67^{\mathbf{a}}$ \\
SE & $\mathbf{4 . 3 9}$ & $\mathbf{6 . 4 1}$ & $\mathbf{9 . 3 8}$ & $\mathbf{1 1 . 3 8}$ & $\mathbf{1 2 . 3 3}$ \\
\hline
\end{tabular}

Means on the same column with the same superscript do not differ significantly from each other $(P=0.05)$. Where: $\mathrm{SE}=\mathrm{Standard}$ error

The effect of $A$. digitata stem-bark powder on percentage mortality of $D$. porcellus were significantly ( $\mathrm{p}<0.05)$ different from day one to five (Table 3 ). Results of the study revealed that total mean values recorded for each treatment increased as the days increased from day one to five. The sample treated with $15 \mathrm{~g}$ of $A$. digitata stem-bark powder gave the highest value from day one to five and the order of increase were $15 \mathrm{~g}>10 \mathrm{~g}>5 \mathrm{~g}>0 \mathrm{~g}$ (control). The stem bark powder showed it effect on the studied insect in different ways. According to Loko et al. (2017), this could be attributed the physiological features of the insect species as well as the kind of the botanical. The synergetic effect of $A$. digitata leaves and stem-bark powder on percentage mortality of $D$. porcellus were significantly $(\mathrm{p}<0.05)$ different from day one to five (Table 4). Results of the study therefore revealed that total mean values recorded for each treatment also increases as the days increased from day one to five. The sample treated with $15 \mathrm{~g}$ of the combination of $A$. digitata leaves and stem-bark powder gave the highest total value and the order of performance from day one to five were $15 \mathrm{~g}>10 \mathrm{~g}>5 \mathrm{~g}>0 \mathrm{~g}$ (control). Combinning the various plant parts did not enhance insect mortality and the effect is dose dependent. This is similar with the study of Oladejo et al. (2020) who 
indicated insecticidal effects of stem bark and leaf powders combination in controlling $S$. zeamais were not very effective. The effect of plant extracts on percentage mortality shows significant difference $(\mathrm{p}<0.05)$ on the $1^{\text {st }}, 2^{\text {nd }}$ and $3^{\text {rd }}$ day but nonsignificantly different at the $4^{\text {th }}$ and $5^{\text {th }}$ day. The result showed that mortality of D.porcellus caused by the various doses of stem-bark, leaf and stem-bark + leaf powders used was higher when compared with those observed in the negative control. From the results on Table 5, stem-bark powder show highest effect on mortality of $D$. porcellus and the order of increase were stem-bark powder $>$ Leaf powder + Stem-bark powder $>$ leaf powder. The biocidal activity of $A$ digitata is majorly as a result of flavonoids, alkaloids, tannins and saponins (Ubulom et al., 2012) and this might has led to insect mortality in this study. Flavonoids exhibit antifeedant effect against insects and herbivores that attack plants (Acheuk and Doumandji-Mitiche, 2013). According to Padin et al. (2013) botanicals like A digitata contain phytochemicals which are toxic and lead to death of insect pests found in storage. Alkaloids content of Arachis hypogaea extract exhibited larvicidal activity against malarial vectors (Velu et al., 2015). Death of insects arises due to insect spiracles blockage by dust particles of pulverized powder of botanical (Fernando and Karunaratne, 2012). In another report, botanicals also gain entrance into insect body through the respiratory system and cause death (Kedia et al., 2015).

Conclusion: This study revealed the insecticidal potentials of powder of leaf and stem bark of Adansonia digitata against $D$ porcellus. Significant difference $(\mathrm{p}<0.05)$ was observed on the mortality between the treated yam chips and the controls. Thus, powder of Adansonia digitata leaf and stem bark can serve as alternative means of preventing and controlling yam chips infestation caused by $D$. porcellus. Further research is required to ascertain the efficacy of seed, fruit and root bark of Adansonia digitata on D. porcellus.

\section{REFERENCES}

Acheuk, F; Doumandji-Mitiche, B (2013). Insecticidal Activity of Alkaloids Extract of Pergularia tomentosa (Asclepiadaceae) against Ffth Instar Larvae of Locusta migratoria inerascens (Fabricius 1781) (Orthoptera: Acrididae). Inter. J. Sci. Adv. Technol. 3(6), 8-13.

Adeleke, SI (2009). Food Poisoning Due to Yam Flour Consumption in Kano (Northwest) Nigeria. The Online J. Health. Allied Sci., 8(2):10.
Adesuyi, SA (1979). The Problems of Insect Infestation of Stored Yam Chips in Nigeria. Proceedings of the Second International Working Conference on Stored Product Entomology; 1978 Sep 10-16; Ibadan, Nigeria. 314-319.

Amusa, NA; Adegbite, AA; Muhammed, S; Baiyewu, RA (2003). Yam Diseases and its Management in Nigeria. Afri. J. Biotechnology, 2 (12):497-502.

Asawalam, EF; Emosairue, SO; Hassanali, A (2006). Bioactivity of Xylopia aetiopica (Dunal) a Rich Essential Oil Constituent on Maize Weevil Sitophilus zeamais Motch (Coleoptera: Curculionidae). Electronic J. Environ. Agric. Food Chem. 5:1195-1204.

Babajide, JM; Oyewole, OB; Henshaw, FO; Babajide, SO; Olasantan, FO (2006). Effect of Local Preservatives on Guality of Traditional Dry-Yam Slices "Gbodo" and its Products. World J. Agric. Sci. 2(3):267-273.

Babarinde, SA; Babarinde, GO; Odewole, AF; Alagbe, OO (2013). Effect of the Prevalent Insect Species of Yam Chips on Consumers Acceptability of Yam Past. J. Agric. Ext. Rural Develop. 46(3): 97-101.

Chebet, F; Deng, AL; Ogendo, JO; Kamau, AW; Bett, PK (2013). Bioactivity of Selected Plant Powders against Prostephanus truncates (Coleoptera: Bostrichidae) in Stored Maize Grains. Plant Protection Science, 49(1):34-43.

FAO (1998). Food and Agriculture Organization Production Year Book FAO Rome. 5.

Fernando, HS; Karunaratne, MM (2012). Ethnobotanicals for Storage Insect Pest Management: Effect of powdered leaves of Olax zeylanica in suppressing infestations of rice weevil Sitophilus oryzae (L) (Coleoptera: Curculionidae). J. Tropical Forestry and Environ. 2(1):20-25.

Harborne JB. (1984). Phytochemical Methods: A Guide to Modern Techniques of Plant Analysis, Edn 2, Chapman and Hall, London.

Kedia, A; Prakash, B; Mishra, P.K; Singh, P; Dubey, NK (2015). Botanicals as Ecofriendly Bio-rational Alternatives of Synthetic Pesticides against Callosobruchus spp (Coleoptera: Bruchidae)-a review. J. Food Sci. Technol. 52(3):1239-1257. 
Kumar, P; Bhadauria, T; Mishra, J (2015). Impact of Application of Insecticide Quercetin/Azadirachtin and Chlorpyrifos on Earthworm Activities in Experimental Soils in Uttar Pradesh India. Science Postprint, 1(2), e00044.

Loko, YI; Gnaho, AC; Orobiyi, A; Agre, P; Dangi, A (2017). Resistance of Dried Chips Yam Dioscorea cayenensis- D. rotundata omplex) Landraces to Dinoderus porceliuslesine (Coleopteran Bostrictide). Cogent food and Agriculture, 3(1): 141-180.

Loko, YLE; Toffa, Dèca, MJ; Orobiyi, A (2019). Integrated Pest Management of the Yam Chip Beetle Dinoderus porcellus Lesne (Coleoptera: Bostrichidae): Current Status and Future Prospects. DOI: http://dx.doi.org/10.5772/intechopen.87926.

Musau, JK; Mbaria, JM; Nguta, JM; Mathiu, M; Kiama. SG (2016). Phytochemical Composition and Larvicidal Properties of Plants Used for Mosquito Control in Kwale County, Kenya. International Journal of Mosquito Research, 3(3): 12-17.

Oladejo, AO; Sikiru, GK; Popoola, AS; Adedire, O; Olori-oke, O (2020). Insecticidal Effects of Gmelina Arborea Stem Bark and Leaf Powder on Sitophilus zeamais (Maize weevil) on Stored Maize Grains. Journal of Africa Sustainability development, 18(2):225-234.

Onzo, A; Biaou, JT; Loko, LT; Tamo, M; Dansi, A (2015). Vulnerability des cossettes issues de quelques cultivars digname a I' attaque de Dinoderus pocelluslesne (coleopteran bostrichidae) en conditions de laboratoire. International journal of biological and chemical sciences
Padin, SB; Fuse, C; Urrutia, MI; DalBello, GM (2013). Toxicity and Repellency of Nine Medicinal Plants against Tribolium Castaneum in Stored Wheat. Bulletin of Insectology, 66(1), 45-49.

Ubulom, PME; Imandeh, GN; Ettebong, EO; Udobi, CE (2012). Potential Larvicidal Properties of Blighia sapida Leaf Extracts against Larvae of An. gambiae, $\quad \mathrm{Cu}$. quinquefasciatus and Ae. Aegypti. British Journal of Pharmaceutical Research, 2(4): 259-268.

Velu, K; Elumalai, D; Hemalatha, P; Babu, M; Janaki, A; Kaleena, PK (2015). Phytochemical Screening and Larvicidal Activity of Peel Extracts of Arachis Hypogaea against Chikungunya and Malarial Vectors. International Journal of Mosquito Research, 2(1), 01-08.

Vernier, P; Goerge, G; Dossou, RA; Letourmy, P; Chaume, J (2005).Utilization of Biological Insecticides for the Protection of Stored Yam Chips. Outlook on Agriculture, 34(3): 173 -179.

Zagga, AI; Abduljabbar, IA; Garko, MBA; Tsoho, B; Gbande, S (2018). Phytochemical Composition of Adansonia digitata L. Leaf Extracts. Proceedings of 6th NSCB Biodiversity Conference; Uniuyo, (300 304). 